\title{
Les littératures maghrébines face à la critique, dossier coordonné par Guy Dugas
}

\section{Paola Martini}

\section{(2) OpenEdition}

1 Journals

\section{Edizione digitale}

URL: http://journals.openedition.org/studifrancesi/30871

DOI: 10.4000/studifrancesi.30871

ISSN: 2421-5856

\section{Editore}

Rosenberg \& Sellier

\section{Edizione cartacea}

Data di pubblicazione: 1 avril 2006

Paginazione: 198-199

ISSN: 0039-2944

\section{Notizia bibliografica digitale}

Paola Martini, «Les littératures maghrébines face à la critique, dossier coordonné par Guy Dugas», Studi Francesi [Online], 148 (XLX | I) | 2006, online dal 30 novembre 2015, consultato il 18 avril 2021. URL: http://journals.openedition.org/studifrancesi/30871; DOI: https://doi.org/10.4000/studifrancesi. 30871

Questo documento è stato generato automaticamente il 18 avril 2021.

\section{(c) (1)}

Studi Francesi è distribuita con Licenza Creative Commons Attribuzione - Non commerciale - Non opere derivate 4.0 Internazionale. 


\title{
Les littératures maghrébines face à la critique, dossier coordonné par Guy Dugas
}

\author{
Paola Martini
}

\section{NOTIZIA}

"Expressions maghrébines", Les littératures maghrébines face à la critique, dossier coordonné par Guy DUGAS, vol. 4, 1, été, 2005, pp. 177.

1 Il nuovo numero del semestrale di cultura maghrebina ha come intento quello fare il punto sulla critica concernente la letteratura del Maghreb. Guy Dugas, in Petite réflexion critique sur les prix littéraires au Maghreb en période coloniale et postcoloniale, riflette sul ruolo che hanno avuto, ed hanno tuttora, i premi letterari nel Maghreb coloniale e postcoloniale, sul loro impatto nei confronti dei lettori locali e metropolitani e, infine, sulla loro influenza nel mondo dell'editoria. Dalla ricerca dello studioso emerge che alcune istituzioni prestigiose come la SEAN (Société des Écrivains de l'Afrique du Nord fondata a Tunisi nel 1920) hanno a lungo privilegiato una logica assimilazionista che considerava il Nord Africa un territorio dalla cultura omogenea, tanto da prevedere un unico premio letterario per il Marocco, l'Algeria e la Tunisia. È stato così che in seguito associazioni di scrittori e governi locali hanno pensato di dar vita ad altri enti preposti al giudizio e alla premiazione di autori all'interno di ogni singolo paese. Un altro problema su cui viene posto l'accento nell'articolo concerne l'editoria: una realtà commerciale che nel Maghreb è ancora debole e può contare su una diffusione modesta e su una critica ancora poco presente.

Il contributo di Michael Peyron, Bringing Berber Literature Out of the Academic Wilderness, è un'analisi diacronica concernente lo studio della cultura berbera. Dopo un periodo di bilinguismo risalente al Medioevo, il berbero è stato a poco a poco marginalizzato e ridotto al rango di sub-cultura. In epoca recente è riuscito a riconquistare, non senza 
fatica, una certa importanza nell'ambito degli studi berberi post-coloniali, i quali in Francia hanno tuttavia privilegiato l'aspetto linguistico a scapito della raccolta di testi. È solo tra gli anni Ottanta e Novanta che gli etnologi anglosassoni hanno dato un nuovo e più proficuo impulso agli studi sulla cultura amazighe. Attualmente, conclude Michel Peyron, la lingua e la cultura berbera sono riconosciute come componenti del patrimonio marocchino. Nadine Le Duff in De la créolité au rythme, du rythme au chaos, et retour...Un essai de lecture des textes francophones maghrébins ricorre alla nozione di créolité per affrontare la critica del testo maghrebino. Il concetto di creolité, rimettendo in discussione l'idea di purezza e unicità soggiacenti alla nozione di identità, diventa pregnante nell'approccio di una letteratura come quella maghrebina ove confluiscono elementi culturali e linguistici fortemente eterogenei. Nadine le Duff si richiama infine alla poetica del ritmo di Henri Meschonnic, la quale permette uno studio della letteratura come «mise en mouvement d'une parole» (p. 39) in grado di valorizzare la componente orale dei testi.

3 La seconda parte della rivista si apre con un articolo di taïeb Berrada, dal titolo $D u$ plagiat d'auteur à l'identité beur dans "La fin tragique de Philomène Tralala" de Fouad Laroui. Lo scrittore Fouad Laroui ricorre allo scandalo dei plagi rinvenuti nei testi di Calixte Beyala per creare un romanzo che, nella scelta dello pseudonimo (si noti l'assonanza tra Beyala e Tralala) e dei contenuti, ricorda la vicenda autobiografica della scrittrice camerunense. Berrada evidenzia punto per punto come Laroui riesca a dar vita ad un paratesto in grado di sviluppare un discorso sulla proprietà letteraria e sulla liceità dell'appropriazione, sia essa letteraria o culturale. La tesi dello scrittore sembra alla fine propendere per una demitizzazione del concetto di autore. Martine Fernandes, in Francophonie, postcolonialisme et lingiustique cognitive: la métaphore de la guerre dans trois romans féminins algériens, constata che gli studi francofoni sono ancora emergenti in Francia e limitati ad un campo strettamente culturale, che ha tratto impulso dall'affermazione dei postcolonial studies nei paesi anglosassoni. Alla luce di tali limiti, scrittici algerine come Assia Djébar, Farida Belghoul e Nina Bouraoui deplorano la mancanza d'interesse da parte della critica nei confronti della loro lingua e del loro stile. La curatrice del contributo, ispirandosi alle teorie della linguistica cognitiva, evidenzia, al termine dell'articolo, come la guerra possa essere interpretata in termini metaforici e come essa si situi alla base dell'hybridité identitaria e testuale in L'amour, la fantasia di Assia Djébar, in Georgette! di Farida Belghoul e Garçon manqué di Nina Bouraoui. In Mémoire personnelle et collective dans "Je ne parle pas la langue de mon père" et "Mes Algéries en France" de Leila Sebbar, Mildred Mortimer propone di esaminare i due testi sopracitati della scrittrice franco-maghrebina, dalla lettura dei quali si evincerebbe che la storia collettiva sia un mosaico di storie individuali. Nelle sue opere - spiega la curatrice - la Sebbar sottolinea l'importanza di riscrivere la storia per colmare, ricorrendo all'autobiografia e all'immaginazione, il vuoto di un gran numero di persone rimaste in silenzio. Solo attraverso la testimonianza degli altri la scrittrice pare poter comprendere appieno il proprio passato e creare "la suture qui masque la blessure, l'écart, entre les deux rives" (p. 99).

4 La figura di Hélène Cixous è al centro dell'articolo Signifiant discursif et dévoilement de l'inconscient: une maladie textuelle et «arabizarre» a cura di Maribel Peñalver Vicea. Il contributo mette in luce come la scrittura onirica della Cixous diventi un rifugio, una sorta di luogo in cui niente è proibito e dove è possibile dar voce anche ai fatti più crudeli vissuti dalla scrittrice. Grazie ad una lingua tormentata e frantumata la 
scrittura può spingersi fino a dire le sofferenze più intime. La lettura polisemica delle sue opere evidenzierebbe così transfert semantici in grado di rivelare gli strati più profondi dell'inconscio in cui la scrittrice e la donna si mettono a nudo. Laura Loth, in Epigraph-Effect/Eberhardt-Effect: the Death of Legend in Malika Mokeddem's "Le Siècle des sauterelles", riflette sull'arbitrarietà e sui limiti del concetto di identità prendendo in esame la vita e la leggenda di Isabelle Eberhardht. La lettura di Siècle des sauterelles di Malika Mokeddem suggerisce - secondo la Loth - il dovere da parte della letteratura di creare uno spazio in cui biografia e leggenda possano essere ridefinite alla luce di nuovi approcci critici e delle nuove esigenze di un pubblico sempre più vasto ed eterogeneo. La rivista chiude con un nuovo contributo su Malika Mokeddem, a cura di Anne Marie Miraglia, dal titolo L'errance chez Malika Mokeddem: entre l'exil et l'impossible retour. Attraverso la lettura di tre romanzi - Les hommes qui marchent (1990), L'Interdite (1993) e Des rêves et des assassins (1995) - viene tracciato il lento e travagliato percorso delle protagoniste femminili verso l'esilio, presentato come evasione necessaria, come rifugio e come fuga. Qualunque sia il contesto storico - la guerra d'Algeria o la guerra civile - le protagoniste della Mokeddem trovano la salvezza solo nell'erranza, in un "ailleurs géographique, psychique et culturel" (p.155). In proposito diventa significativo osservare, come viene suggerito nell'articolo, che Zohra, in Les hommes qui marchent, decide di interrompere il proprio cammino ai piedi della duna, alla frontiera tra il mondo sedentario e quello nomade. 